\title{
Cultural centres: a future for cultural Arctic tourism?
}

\author{
Elizabeth Ann Cooper
}

\begin{abstract}
Purpose - The purpose of this paper is to examine the potential of cultural centres to be spaces that foster interaction between tourists and locals, and thereby meet the demands of new cultural tourists. This is done through conducting a case study of Katuaq Cultural Centre in Nuuk, Greenland. Combining theories of cultural contact and placemaking, the paper analyses how locals and tourists make use of and experience the centre. The paper then goes on to conduct a broader discussion about how future placemaking in tourism can respond to the emerging demands of cultural Arctic tourists, and to suggest ways to encourage positive interaction on both a local community level and a resident-visitor level.

Design/methodology/approach - A series of anthropological research methods were used, including participant observation in the cultural centre itself, and informal and semi-structured interviews with relevant stakeholders.

Findings - Concluding that, from multiple perspectives, Katuaq fails to perform as a "centre of culture", the study offers innovative insights into how cultural centres can be operated more inclusively in the future, as spaces in which members of different cultural groups can achieve positive interaction. It is argued that the future of successful and fulfilling cultural tourism offerings in the Arctic lies at the intersection of tourism and leisure studies.

Originality/value - The originality of this paper lies first in its deepening of the academic discussion of cultural centres. Second, and on a broader level, the paper identifies an emerging trend of "community-tourism spaces" as cultural tourism offerings, and provides some insights into the conflicts experienced in these kinds of spaces, as well as some suggestions as to how further research on these spaces should continue.
\end{abstract}

Keywords Cultural Tourism, Placemaking, Local community, Tourism futures, Contact zones,

Cultural encounters

Paper type Research paper

\section{Introduction}

Tourism is relatively new to Greenland, with approximately 90,000 tourist arrivals registered in 2017 (Tourismstat.gl, 2018). It is, however, growing at a notable rate, and in particular in the capital city of Nuuk, where previous market research has revealed that the amount of cultural activities on offer does not meet tourist demand (Visit Greenland, 2018). Nuuk is often perceived by tourists as somewhere that is a window onto ordinary life in Greenland, and where impromptu contact with locals is often named as the most memorable experience (Visit Greenland, 2018); the future increase in tourism to Nuuk looks set to demand even more immersive cultural experiences.

According to Richards (2007), "the (cultural) tourist (seeks) an experience of the "Other" that does not produce culture shock or go as far as a reversal of the home culture" (Richards, 2007, p. 7). The author argues that cultural tourists, to some extent, seek an experience that reflects the banalities of their everyday life. He continues: "Cultural tourism [...] is not so much a process of reversal, but is in fact an extension of everyday life" (Richards, 2007, p. 7). This balance of cultural tourists seeking "Otherness", whilst simultaneously seeking a reflection of their own everyday life, exposes one of the perpetual dilemmas of tourism studies: how to generate natural interaction, or at least the natural sharing of space, between hosts and guests.
Elizabeth Ann Cooper is

Former Master's student at the Department of Culture and Global Studies, Aalborg University, Copenhagen, Denmark.

Received 18 January 2019 Accepted 20 September 2019

(C) Elizabeth Ann Cooper. Published in Journal of Tourism Futures. Published by Emerald Publishing Limited. This article is published under the Creative Commons Attribution (CC BY 4.0) licence. Anyone may reproduce, distribute, translate and create derivative works of this article (for both commercial and non-commercial purposes), subject to full attribution to the original publication and authors. The full terms of this licence may be seen at http://creativecommons.org/ licences/by/4.0/legalcode 
Cultural centres, often being used simultaneously as community meeting spaces and as tourist attractions, have the potential to be spaces that foster these meetings and meet the demands of today's cultural tourists - by being places in which tourists are welcome to simply "be" among the local community who are living out their daily lives.

Katuaq, meaning drumstick in Greenlandic, calls itself not just the cultural centre of Nuuk but the cultural centre of the whole of Greenland, being the largest and longest established cultural centre in the country. It was opened in February 1997 and constructed as a joint project of the Greenland Home Rule Government, the Nuuk Municipal Council and the Nordic Council of Ministers (Katuaq, 2017). The building was constructed using public money, but now receives its income partly from the government and partly through private revenue. Inside Katuaq, the large foyer acts as a café, restaurant, exhibition space and a concert hall. There is also a cinema and theatre space, and numerous conference rooms, meeting rooms, rehearsal rooms and offices within the building (Plates 1 and 2).

Katuaq is often described by its management staff as a "melting pot" and a place for everyone (Interview with Paninnguaq, member of Katuaq's management staff; interview with Agnes, member of Katuaq's management staff). Katuaq's publications use inclusive discourse to imply that Katuaq is a place that has an obligation to members of all social groups, simultaneously presenting the centre as a community space and as a place for tourism (Katuaq, 2017). It is certainly portrayed as somewhere that could generate natural interaction between locals and tourists.

This paper first investigates to what extent Katuaq is in fact a space that fosters natural interaction between locals and tourists, by examining how it is used and perceived by different stakeholders. After briefly outlining my methods, I present in more detail Katuaq's purpose and mission. I then explain the reasoning behind my chosen theoretical foundations. After this, I analyse the use of Katuaq based on each of these theories, and use the findings to discuss an answer to the question of the extent to which Katuaq successfully fosters host/guest interaction. This leads on to the discussion section, which focusses on the relevance of cultural centres to cultural tourism in the future. Practical steps are suggested that can be implemented across cultural centres in general, in order to work towards making them spaces that can successfully host both local

Plate 1 Katuaq cultural centre - exterior

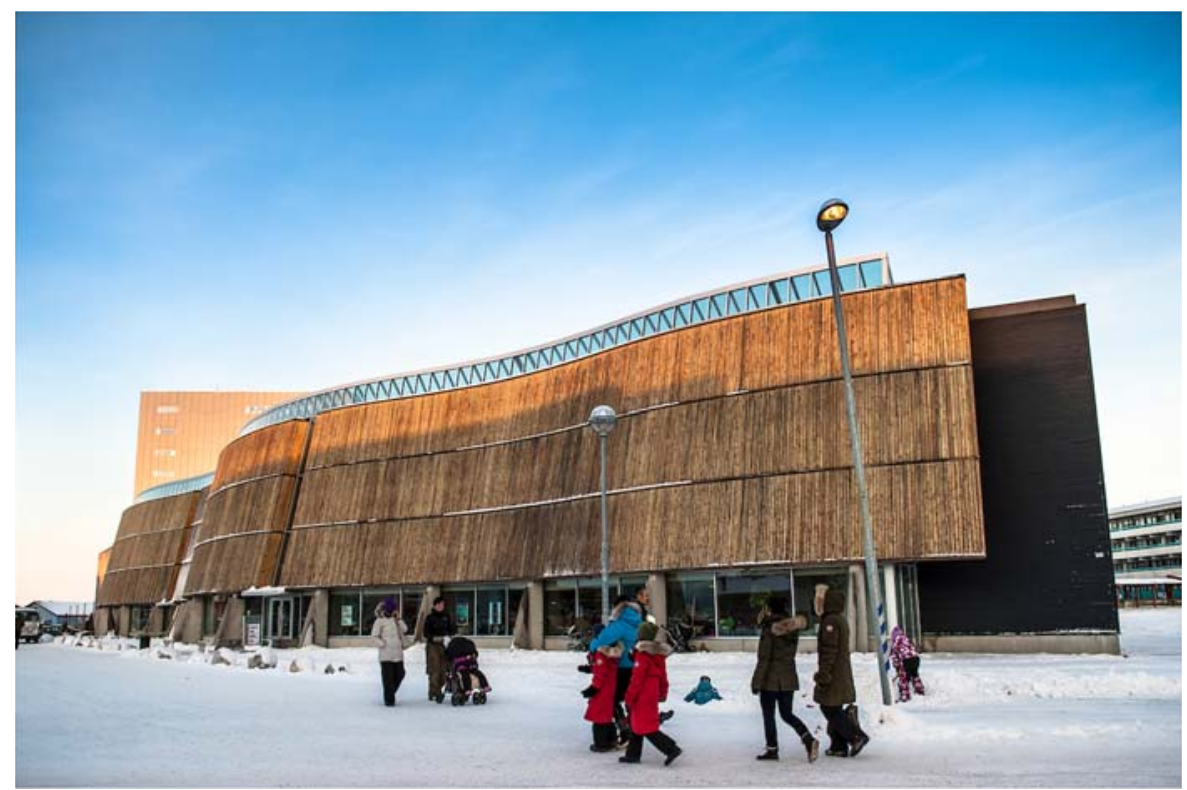

Source: Photo by Camilla Hylleberg - Visit Greenland 


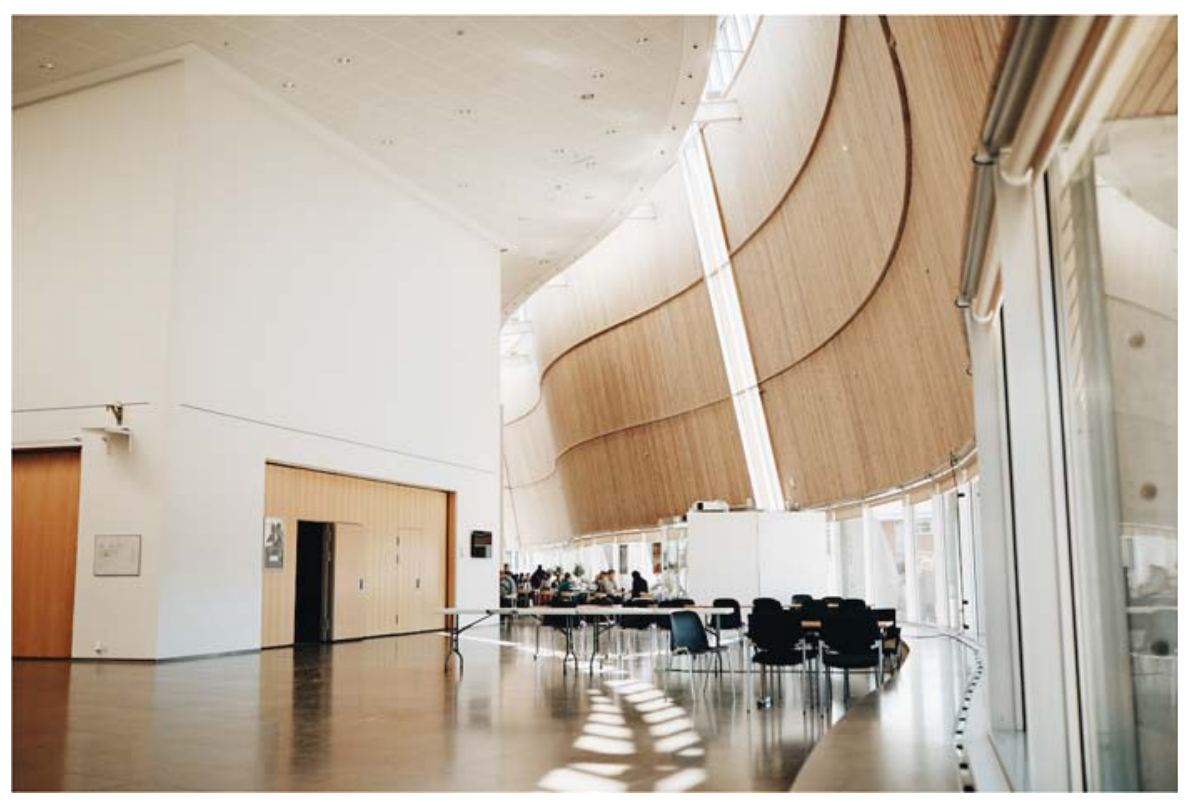

Source: Photo by Filip Gielda - Visit Greenland

communities and tourists, and thereby contribute to the generation of natural and beneficial host-guest interaction. The final part of the discussion outlines the relevance of this study for further academic research in the study of both tourism and leisure.

\section{Methods}

I conducted fieldwork in Nuuk for four weeks in early 2018, using anthropological research methods. Three months' previous experience working in Greenland in summer 2017 had given me a basic understanding of the country and the culture and enabled me to form relevant contacts.

My methods were shaped primarily by an inductive approach, which aims to let the researcher's experiences in the field determine the direction of the research (Hannam and Knox, 2011, p. 179). It is argued that inductive research produces knowledge that is most representative of the social world in action (Hannam and Knox, 2011, p. 179), although inevitably there were elements of deductiveness applied at certain points throughout the process of analysis and writing up. When I finally decided on my theoretical framework, for example, I was forced to structure my arguments according to the chosen theories.

In order to ensure a primarily inductive approach, I employed anthropological research methods, such as participant observation, which is argued to be particularly appropriate for the study of an ongoing, everyday social process which requires the understanding of human perspectives (Hannam and Knox, 2011; Bernard, 2011; Jorgensen, 1989/2011). My participant observation mainly took the form of attending events at Katuaq and spending time in the café area observing everyday happenings at the venue. I recorded my observations in a fieldwork diary which I updated daily.

Throughout my fieldwork, I conducted informal interviews as a method of building closer and more trusting relationships with informants, in the hope that this would make them more relaxed during a recorded, semi-structured interview. I also conducted informal interviews with tourists I had met during my time in Nuuk in summer 2017. Informal, or unstructured, interviews establish only a broad topic prior to interview, rather than planning individual questions: "the intention here is to allow the research subject to set the agenda and to tailor each interview to the interviewee" 
(Hannam and Knox, 2011, p. 182). The bulk of the data was collected using audio-recorded, semi-structured interviews. These are "relatively informal, open to the input and direction of both the researcher and research subject, and are partially structured through the use of a one-page or so interview checklist or schedule" (Hannam and Knox, 2011, p. 182). This means that the interview can adapt to unexpected material, and that knowledge developed through the process is socially constructed between both researcher and interviewee (Hannam and Knox, 2011, p. 182). In conducting my semi-structured interviews, I outlined some topics beforehand, but largely let my respondents guide the conversation. This was intended to empower informants to present their own worldview, and to enable me to understand this as comprehensively as possible.

I recorded 16 semi-structured interviews in total. Informants included three members of management staff in Katuaq, three employees at Katuaq, five local cultural artists and five local users of Katuaq. Many respondents are well-known personalities in Greenlandic cultural society, and often expressed controversial opinions about the topics we discussed. Although they did not seem particularly shy about their views, I have decided to change their names for the sake of ethics and fairness to those who were kind enough to share their time and their thoughts with me.

After concluding my fieldwork in Nuuk, I transcribed, coded and analysed the data in order to reach my conclusions.

\section{Theoretical background}

There is little existing scholarship on the phenomenon of cultural centres, which makes defining a theoretical basis rather difficult. Since the concept of culture is multifaceted, open to interpretation, and constantly evolving (Clifford, 1988; Ortner, 2006; Stern and Stevenson, 2006), it follows that cultural centres as spaces are not easily defined. What little literature there is identifies them sometimes as museums for disseminating local culture to tourists (Wachowich, 2006), sometimes as spaces that belong to indigenous communities (Bresner, 2014), and sometimes as places for the revitalisation of "traditional" cultural practices (Alivizatou, 2011).

In order to build a relevant theoretical background, therefore, I look not to existing literature on cultural centres, but into Katuaq's self-proclaimed mission and purpose, and construct a theoretical basis from that.

\subsection{An introduction to Katuaq: purpose and mission}

Katuaq is frequently portrayed as a place for everyone: "It's a house where everyone feels welcome [...] It's one that is able to attract many different kinds of people" (Interview with Agnes, member of Katuaq's management staff). This is echoed in publications produced by Katuaq: "It's extremely important for our city as the nation's capital to have a cultural centre, because it's everyone's centre. Culture belongs to everyone" (Katuaq, 2017, p. 83). The phrase "culture is for everyone" takes ownership and authority regarding culture away from the managers of the centre and places it in the hands of people collectively. It suggests that everyone, regardless of social group, has the right to experience culture through a cultural centre. This inclusive discourse implies that Katuaq is a place that has an obligation to the public, and to members of all social groups.

Simultaneously, however, Katuaq aims to present itself as a community space: "Katuaq is the equivalent to my childhood local hall" (Katuaq, 2017, p. 18), and as having an international outlook as well: "A stage in Greenland for the presentation of artistic activities from other countries, and a place from which artistic activities can be helped further out in Greenland and possibly further internationally" (Katuaq, 2017, p. 15).

There is also evidence that the centre wants to present itself as a place specifically for tourism: "It's a place for people coming from other countries visiting Nuuk. Everyone who visits Nuuk comes to the place, or should at least come to the place" (Interview with Paninnguaq, member of Katuaq's management staff). These quotes imply that Katuaq, as well as being a space for the strengthening of the local community, also wants to be a place for international participation and an international audience. According to Paninnguaq, it is also a "must-visit" site for tourists. In this 
way, Katuaq portrays itself as somewhere that is not just for everyone, but that appeals specifically to each different audience simultaneously, for different reasons.

This analysis of the public face of Katuaq identifies that it is working with many different purposes and missions simultaneously. It aims to be a public space, a private space and a space that physically plays many different roles. It claims to be a space that is used by the community, by tourists, and also a platform for the playing out of intercultural meetings.

I can argue, therefore, that Katuaq aims to be a space that fosters positive interaction between the local community and tourists. This is a commendable mission, and one which places this case study firmly within the realm of tourism studies, since it encourages positive cultural encounters between hosts and guests, which it has been argued is what today's cultural tourists increasingly seek. The strong community element to the centre, however, introduces, unavoidably, the field of leisure studies.

\subsection{At the intersection of tourism and leisure studies}

Katuaq's mission and purpose places it at the intersection of tourism and leisure studies. Since it aims to act as an open space for the meeting of different social groups from the local community, it is logical to use theories from leisure studies to analyse how effectively it meets this aim. It is also relevant to use theories from the realm of tourism studies to analyse if, and how, cultural encounters occur between visitors and residents. Approaching this case study through the lens of tourism studies adds a more interesting and complex dynamic to the analysis of a community space; while there exists plenty of research on the social encounters that occur within a shared community space (Oldenburg and Brissett, 1982; Glover, 2004; Shinew et al., 2004; Slater and Jung Koo, 2010; Crick, 2015; Aelbrecht, 2016), there is not so much that looks at residential encounters and resident-guest encounters simultaneously. As it is argued that "new cultural tourists" increasingly seek access to everyday life in tourism destinations (Richards, 2007; Visit Greenland, 2018), this intersection of tourism and leisure studies is an appropriate theoretical approach to use to discuss the future of cultural tourism as it manifests in local community spaces.

My analysis is structured using three main theories. To cover the community element, I use the theory of third places (Oldenburg and Brissett, 1982; Slater and Jung Koo, 2010; Schorch, 2013; Crick, 2015; Aelbrecht, 2016). To discuss encounters between different groups of people (both local community groups and resident vs visitor groups), I use contact theory (Allport et al., 1954; Suchman, 1964; Jackman and Crane, 1986; Shinew et al., 2004), and to locate these encounters specifically within tourism, I use theories of contact zones (Pratt, 1991; Bruner, 2005; Selka, 2013).

\section{Analysis}

\subsection{Third places}

The term "third place" was coined by Oldenburg and Brissett (1982). They define third places in contrast to the "first place" - the home - and the "second place" - the formal setting of the workplace, school or university (Oldenburg and Brissett, 1982). As such, then, third places are informal spaces that provide opportunities for local people to mix socially - "places where people gather primarily to enjoy each other's company" (Oldenburg and Brissett, 1982, p. 269). Third places are described as welcoming spaces, where users are "psychologically comfortable" (Slater and Jung Koo, 2010, p. 107), where people from all walks of life are welcome and treated as equals, and are free to come and go without obligation (Oldenburg and Brissett, 1982). They are spaces that are seen as "enabling" for users, and as offering opportunities for active participation that members of society cannot receive elsewhere; "they are a forum for "play" in a society interfused with a stubborn commitment to work and purposiveness" (Oldenburg and Brissett, 1982, pp. 282-3). Typical examples of third places might include a library, a community garden, or a café. 
One question that stands out when applying this theory to my study is the question of whether a third place can simultaneously be a tourist space. Oldenburg and Brissett argue that third places are not places that "outsiders find necessarily interesting or notable" (Oldenburg and Brissett, 1982, p. 270). By not appealing to outsiders, it would seem that, by this definition, third places actually are prone to repelling tourists rather than attracting them. Other authors make similar distinctions: "a "Third Place" is not, however, a permanent state, places can lose their character if a particular group dominate with a single purpose or a place changes, for example becomes touristic" (Slater and Jung Koo, p. 101). For Slater and Jung Koo, the influx of tourists is directly responsible for a third place losing its "third place" quality, suggesting that it is impossible for a space to simultaneously be a third place and a tourist space. If Katuaq is to fulfil its claim of providing a space that welcomes both locals and tourists and promotes interaction between them, this is a division that it must overcome.

4.1.1 Katuaq as a third place. Since the term "third place" has been revealed to refer primarily to a space as a meeting place for the local community, I will first analyse how the local community in Nuuk uses Katuaq. One of the main things that stood out to me during data collection and analysis was that many informants, specifically local residents and those involved in the cultural industries, associate a kind of exclusivity with Katuaq. One informant, Maliina, described an "inner circle" relating to the users of Katuaq. This is a feeling that was shared by many other informants - that Katuaq is a place for the higher social echelons. Users of Katuaq are described as "the Caffé Latte segment", and "better educated" (Interview with Arne). Respondents seemed to feel that there are standards in place which make Katuaq inaccessible to working class people: "People who have money usually go to Katuaq [...] Working class people, they don't go into Katuaq often. And they should also have their place. They're also our culture, so where are they?" (Interview with Aka). For Aka, culture denotes everyone; a cultural centre, then, from Aka's perspective, is somewhere that, much like a third place, welcomes all members of society. However, Aka and Arne both argue that access to Katuaq is determined by wealth, rather than simply by membership of local society, or membership of local culture. For these informants, it appears that the culture performed and experienced in Katuaq is not representative of local culture as they see it. If this "elitism" is present, then it follows that Katuaq cannot be considered a third place, since these spaces are characterised by their use by a large proportion of the local community (Oldenburg and Brissett, 1982).

When considering the reasoning for this apparent exclusivity, some informants did not see it as a conscious effort by management to present a limited image of local culture, but rather as a natural result of class divisions in society. The wealth that determines entry into the "Caffé Latte segment" was often associated by informants with an increased adoption of the more "Western" elements of local society. Many informants proposed that perpetuating these Westernisms in turn works to exclude older, more working class and more "Inuit-minded" members of local society. Another reason that was repeatedly cited by informants for the exclusion of some members of local society was a tension between the public and private intentions of Katuaq. Many of my informants view Katuaq as being mainly responsible as a public service and directly questioned the cultural aspect of Katuaq: "It's more commercialised because it's much more like a movie theatre or a conference centre, and where's the cultural part?" (Interview with Igimaq). For local actor Salik, "the business part is heavier. It's very hard to call it 'the cultural centre of Greenland'" (Interview with Salik). These interviewees explicitly connect the concept of culture with a public service, or a responsibility to the public; for them, as a cultural centre, Katuaq is expected to provide opportunities and social development to all members of local society equally. The respondents here create a clear division between commercialisation and culture, implying that a place of culture cannot simultaneously be a place of commerce, or at least be primarily profit driven. This is an apt illustration of the ambiguity surrounding the concept of culture. Since the term is so open to interpretation, it is inevitable that not everyone who has a stake in a cultural centre will have the same expectations from it.

This analysis suggests that class divisions already present in local Nuuk society continue to present themselves or are perhaps even perpetuated, inside the space of Katuaq. This has the effect of rendering the cultural centre (which claims in its publications to be a centre for everyone)

PAGE $62 \mid$ JOURNAL OF TOURISM FUTURES $\mid$ VOL. 6 NO. 12020 
not a third place, since some members of the local community feel excluded from it. In this case, the kind of culture that is performed in Katuaq, from the perspective of my informants, becomes more and more specific as it is moulded by (and in turn influences) ongoing class dynamics in the local community.

\subsection{Contact theory}

The findings from the analysis above echo research by Troy Glover and others which has examined the meeting of different social groups in community gardens (Glover, 2004; Shinew et al., 2004). This research found its basis in contact theory (Allport et al., 1954; Suchman, 1964), which "posits that contact, especially close and contained contact, with members of different racial groups promotes positive, unprejudiced attitudes" (Shinew et al., 2004, p. 337). In other words, that the simple act of enabling contact between people of different social groups will naturally result in positive readjustment of their perceptions of each other. Leisure settings in particular are argued to be ideal environments for this sort of contact, particularly if they function successfully as third places (Shinew et al., 2004, p. 338).

Criticism of contact theory includes the argument that there is a lack of "real-world" studies to demonstrate the phenomenon, and that there are in actual fact a set of specific conditions required for a positive outcome to be possible (Jackman and Crane, 1986; Shinew et al., 2004). In this sense, this case can be considered a contribution to the field as it adds to the collection of real-world studies of the theory.

In Glover's analyses of the social dynamics of community gardens, he found that there was a social structure that was in actual fact perpetuated, rather than dispelled, during the processes of community gardening (Glover, 2004). Those from disadvantaged social groups continued to lack access to the resources that would lend them the ability to have a genuine influence over the garden (Glover, 2004, p. 157). On the question of whether or not this was a deliberate perpetuation of social hierarchy, Glover does not assert that "the core group held deviant aims, but rather that it might have simply worked to achieve its own goals without considering seriously the implications for the other members of the garden network" (Glover, 2004, p. 159). In his view, those at the top of the hierarchy genuinely believed that their actions were in everyone's best interest, but were merely not appreciated by some (Glover, 2004, p. 159).

The case of Katuaq is comparable to Glover's findings in that the centre does appear to perpetuate an already existing social hierarchy in the community. It is also unclear the extent to which this is a conscious decision by management. Nuka, a local actress, recalls a conversation she had with Katuaq management at one of their events:

I [asked] the head people in Katuaq [...] Who can do an exhibition here? They were like, everyone [...] What about the guy in front of Brugsen [a local street market] who does a lot of art and it's good? Can he do an exhibition? Yeah. Does he know that? He's supposed to know [...] Have you told him? No. OK, so you're supposed to have a last name that people know, and you'll be asked by Katuaq if you want to do an exhibition here. (Interview with Nuka)

Although the centre ostensibly very clearly denies the deliberate perpetuation of a social hierarchy (Katuaq, 2017), it appears that some respondents believe the exclusivity they experience in Katuaq is, if not completely deliberate, at least the result of deliberate neglect on the part of management to challenge the existing social structure.

The case of Katuaq, then, challenges the simplicity of contact theory, by offering an example of a case in which contact between different social groups does not only fail to result in positive attitudes but actually in some cases perpetuates or produces negative attitudes towards the other group. This deepens the reasoning for my argument at the end of section 4.1, that Katuaq cannot be seen as a third place.

\subsection{Contact zones}

To incorporate tourists into my theoretical framework, I use the theory of contact zones. This theory builds on contact theory but relates specifically to contact between members of different 
cultures, rather than social groups within one community. Contact zones are defined by Pratt (1991) as: "social spaces where cultures meet, clash, and grapple with each other, often in contexts of highly asymmetrical relations of power, such as colonialism, slavery, or their aftermaths" (Pratt, 1991, p. 34). Pratt, in contrast to the collaborative and progressive atmosphere of third places, does not describe the contact zone as a very pleasant process. It seems that contact zones are not so much places of leisure, as is the case with third places, but are in fact arduous and intense sites of contestation and debate that potentially end in dissatisfaction for some participants (Pratt, 1991, p. 39). Pratt certainly sees contact zones as places of progress and ultimate positivity, however: "along with rage, incomprehension, and pain, there were exhilarating moments of wonder and revelation, mutual understanding, and new wisdom - the joys of the contact zone" (Pratt, 1991, p. 39). The dramas of the contact zone are a means to an end for Pratt; the ultimate and most important purpose of the contact zone is the meeting of cultures and the tackling and readjustment of power relations usually resulting from historic subjugation.

Selka (2013) places the concept of contact zones into the context of tourism. He uses an event - the festival of Boa Morte in Cachoeira, Brazil - as an example of a contact zone, explaining that the festival creates a contact zone between povo de santo, Catholics, evangelicals, Afro-Brazilians and African Americans. For Selka, "the festival provides an excellent opportunity to explore the correspondences and connections between these diverse groups but also the tensions and misunderstandings that vex encounters between them" (Selka, 2013, p. 410). Despite the huge number of potential tensions and struggles created by this event, Selka sees it as an opportunity to progress understanding between cultural groups and look deeper into the connections or disconnections between them.

4.3.1 Katuaq as a contact zone. Despite the fact that the image that Katuaq presents (of being a window onto everyday life in Nuuk) aligns well with many tourists' perceptions of Nuuk, it is not somewhere that is particularly well visited by tourists. Tourists I spoke to reported not going in because it looked shut (Sarah, personal communication), and, when they did go in, only spending time at the café (Lisa, personal communication). During my participant observation in Katuaq during the high season in summer 2017, I also observed that the building is mainly used by tourists for the café; the "cultural" events, such as concerts, were attended almost entirely by locals, although there was undoubtedly a large number of tourists in town. Personally, I found out about these "cultural" events through word of mouth from locals, rather than through any tourist information or marketing channel, so it is not surprising if it was the case that tourists simply were not aware of them. It was also noted by my tourist informants that exposure, specifically that targeted at tourists, is lacking (Sarah, personal communication); this suggests that it is still mainly used as a space for locals.

Views on who Katuaq primarily is for are varied across different stakeholders. In publications, it is portrayed just as much as a tourist site as it is a local gathering space: "Katuaq has become one of the city's landmarks and a place you must experience as a guest [...] Katuaq is Nuuk's emblem" (Katuaq, 2017, p. 28). This kind of communication suggests that Katuaq is a sort of icon for visitors to Nuuk - that it is one of the absolute must-sees. Some informants agreed with this perspective, calling Katuaq "an architectural marvel [...] You can't imagine Nuuk without Katuaq" (Interview with Inuk). However, the theories of placemaking and cultural interactions that are central to this paper rely on much more than simply an impressive façade; although the architecture may act as a draw to attract tourists to the building, it does not guarantee the fulfilment of any deeper demands of cultural tourists.

There is a general consensus among my informants that Katuaq consciously makes its events accessible to Greenlandic speakers; this is an effort which creates inclusivity in the local community, since Greenlandic is the first language spoken in Greenland, but that simultaneously works to exclude tourists, since there are very few international tourists who are likely to speak Greenlandic. Local actress Aka spoke of the themes of the plays that take place in Katuaq: "The plays, they can be very different. In Europe it's like, Shakespeare, but here they are about, I would say Greenlandic culture. Indigenous or colonisation themes" (Interview with Aka). 
These findings suggest that Katuaq presents culture in a compartmentalised fashion: here, the Greenlandic language events can be seen to be accessible only to locals, while the more "Westernised" parts of the building, such as the café, are where tourists feel welcome. Paninnguaq, a member of the management staff at Katuaq, reinforces this suggestion: "The events that happen, the concerts and things like that, they're made for local people [...] Tourists will come to have dinner or a cup of coffee" (Interview with Paninnguaq). Organising Katuaq's programme and the use of its space in this way makes interaction between tourists and locals difficult, despite the fact that both groups use the space. This suggests that Katuaq does not function as a contact zone, in the sense that it does not actively promote cultural meetings and re-negotiations. Constructing a contact zone is about more than simply encouraging different cultural groups to use the same space at the same time; they must both be engaging in the same activity in order for interactions to be fostered (Pratt, 1991; Selka, 2013).

Despite this uncertainty regarding who Katuaq is for, there does seem to be a particular kind of international audience that is important to the building's management. These are the business tourists, or those coming from overseas to attend conferences in Nuuk. Paninnguaq tells me that Katuaq hosts many conferences and is often hired out exclusively for business events: "If the government has a big event or there is a conference, it's in Katuaq you go to those. So it's for representing the country, or being the place that the big events happen" (Interview with Paninnguaq). In this way, then, Paninnguaq does see Katuaq as somewhere that represents Greenland to an international audience, and that is geared towards international visitors, but mainly in a business context rather than a leisure context. This echoes the tension identified previously between public and private responsibilities. Informants who were critical of Katuaq often mentioned conferences as one of the aspects of the centre which is too commercial to represent culture. From this perspective, then, it is interesting to consider that Katuaq's potentially most important international audience is not attracted based on its status as a centre of culture - rather, they are attracted by the facilities that Katuaq can offer as a business event venue. If this is the case, it follows that Katuaq may establish its international presence based on what works well as an event venue and conference centre, rather than on considerations of how local culture should be presented.

Despite Katuaq's popularity among business tourists, I argue that it still does not qualify as a contact zone for two reasons. First, the business tourists often use the space on a private-hire basis, meaning that they are unlikely to come into contact with locals within it (Interview with Panninguaq). Second, the prestigious culture presented to business tourists is not wholly representative of local culture, and so does not necessarily provide the contrast in cultures which characterises a contact zone.

\section{Discussion}

This paper has been built on a theoretical foundation of third places, contact theory and contact zones - theories that all set a foundation for successful and constructive interaction between locals and tourists. The first stage of my discussion, therefore, is to assess to what extent Katuaq currently fulfils these criteria, and, thereby, its own mission and purpose.

My analysis reveals various tensions at work within Katuaq. First, there is a conflict among social classes in Nuuk, and my analysis has revealed this to be very present, and possibly even exacerbated by the way Katuaq currently operates. Second, there is a conflict between locals and tourists, who both use Katuaq but do not find that it allows them interaction with each other. As a result, I conclude that Katuaq does not fulfil the image it presents of itself; the data have shown that it cannot be considered a third place or a contact zone, and that in some cases the kind of contact it enables is perceived as negative. Therefore, it does not fulfil the aims it presents as a cultural centre - of being a meeting space for the local community and for tourists and locals. For the local community, it is not representative of local culture, since it is viewed as inaccessible by some, both in terms of who can perform culture and who can experience culture there. For tourists, it is unfulfilling in terms of cultural representation, since much of the internationally focussed areas seem to be established on commercial aims rather than cultural immersion. It is 
uncommon for the two groups to make contact with each other inside the space, since it is constructed in such a way that tourists and locals use the space for different purposes at different times. Although the data have shown that Katuaq, at different times, acts as many different kinds of places - a place for cultural production, a place for the elite, a place of business, and a place of tourism - it does not succeed in fulfilling these purposes in a way in which they intertwine smoothly with one another, and this is why tensions arise.

Jackman and Crane (1986), when specifying ideal conditions for successful interracial contact, argued that "the setting in which the contact occurs must confer equal status of both parties rather than duplicate the racial status differential" (p. 461). In the case of Katuaq, we do see the meeting of different groups, to an extent, but they do not experience equal status with one another, and this goes some way towards explaining why Katuaq is unsuccessful in its aim of being a "melting pot". The challenges for the future, then, are how to encourage all desired audiences to use the centre; and how to ensure that, when they do use the centre, all groups experience equal social status there.

As we move into an era of "new cultural tourism", in which tourists increasingly expect access to the everyday life of locals, community spaces which are simultaneously welcoming to tourists seem in theory to be the ideal attraction. However, the case of Katuaq shows that it is not as simple as designing a community space and subsequently opening it up to tourists. In other words, the generation of beneficial intercultural interaction is not as simple as those first advocates of contact theory suggested. The problems encountered within Katuaq are relevant to any community leisure space that aims to simultaneously attract tourists, and if we want to successfully incorporate tourists into everyday culture in the future, further research must be conducted on how to foster equal social status for all relevant groups that enjoy the space.

\subsection{Practical steps for successful community-tourism spaces}

Despite my criticism of Katuaq, my research has brought out some practical steps towards making Katuaq (and other community-tourism spaces) more inclusive for both the local community and for tourists in the future. It is apparent that management are aware of the exclusivity and divisiveness that is present in Katuaq, and feel it needs approaching: "That will be interesting for me to dig more into: who are the people who don't come? Why do they not feel that it's a place for them to go?" (Interview with Panninguaq). This suggests that management are already beginning to think about how to foster more inclusivity in Katuaq in the future, and that these practical suggestions can have some impact.

5.1.1 Exercising inclusivity. Inclusivity is not unheard of in Katuaq. Some informants identify certain events which appear to be attended by a majority of the local community. These take the form of free events: "If there are events for free, then people come" (Interview with Aka), or events featuring a widely known artist: "If it's Greenlandic artists, especially if they've been singing for decades and are popular all over the country, then people crowd the place" (Interview with Arne). This suggests that Katuaq can be a place for everyone - but that there are certain conditions. Events must be free and appeal to everyone. Continually organising free events, however, is not really feasible from the perspective of a partly private, for-profit business, and finding events that will appeal to both the majority of the local community and to the majority of tourists could prove difficult. The kind of community-tourism space that could benefit from the hosting of free and attractive events would need to receive heavy funding or subsidies.

5.1.2 Constructing a creative space. Much of the dissatisfaction with Katuaq, for respondents who work in the creative industries, comes from a perceived lack of creativity within the centre. Many informants imagine that constructing spaces in which visitors can watch artists create will generate interest for both locals and tourists:

The tourists love this building. But if it worked as it should be working, it would be even more popular. People [...] could look into Greenlandic artists being creative. Doors should be opening - not just a conference hall, not just a cinema. It could be so much more [...] I would love to be able to say, I'm going to Katuaq tomorrow at 8 . I want to see these guys printing photography, inside what used to be a kitchen. And I would like to see a local artist paint her paintings, have a cup of coffee with her, it's 
open to the public - she opens her studio. She welcomes visitors from 7 to 8 [...] Without the integration you wouldn't have any dialogue or feedback [... I If I had the photo studio, I would be happy to invite school kids: would you like to see how I develop a film roll? It should be that kind of place. (Interview with Inuk)

Here, Inuk, a local artist and photographer, envisages a situation in which Katuaq's rooms are used for creative purposes - as studios and workshops, and rented out to local artists for them to create in. Visitors to Katuaq would be invited into the studios to interact with the artists and watch them work. For Inuk, this setup would be beneficial for the artists themselves, since they would receive input on their work from visitors, and for the visitors, as they can witness culture being created, learn about artistic processes and have dialogue with local artists.

Refocusing attention on the production of culture rather than its appreciation could be an effective way of levelling out inherent social structures. While the appreciation of culture in Katuaq currently appears to deepen social divisions (as a result of implications about which art it is "worth" exhibiting in the centre), involving visitors in the production process could potentially dispel these assumptions.

5.1.3 Doing cultural tourism differently. Some of the difficulty in seeing Katuaq as somewhere that can cater for both locals and tourists simultaneously originates from an assumption that tourists are only interested in events which are designed specifically for them: "If you're going in for a local cultural experience as the locals would do, you have all these. But if you expect an event that is for you as a foreigner coming to Greenland, it's not" (Interview with Panninguaq). It seems from this quote that Panninguaq views events for foreigners as having to be specifically tailored towards foreigners. However, as is argued in the Introduction, it is not necessarily the case today that cultural tourists need products that are specifically targeted at them. On the contrary, it is argued that cultural tourists are increasingly seeking opportunities to experience locals' everyday life play out in front of them (Richards, 2007). Maliina seems to agree with this theory:

I think they have to stick to the part that's actually their name, a "cultural house", and not try to be so global. Because the culture house is not supposed to be global, it's supposed to be cultural [...] They should celebrate the cultural parts. Not the global services [...] And I think that that would make Katuaq

much more appealing for other people, like, everyone. (Interview with Maliina)

Maliina sees a division between representing culture and adopting a global mindset. To her mind, Katuaq's focus on an international audience removes some of its cultural element. Conversely, she sees a more local focus as attracting a global audience; by actively focussing on the local culture, she argues that those outside the local culture would be attracted to Katuaq. In this sense, if it is an attraction for tourists simply to witness local people going about their everyday lives, then community-tourism spaces do not need to be places that are overtly constructed for tourism. They simply need to be places that are used on an everyday basis by the local community, but which also welcome international visitors on an equal level. If the attitude of management is that it is enough for cultural tourists to have access to a space in which locals live out their everyday lives, then there is room for spaces, in the future, to be aimed towards a local audience yet simultaneously attract a global audience.

\subsection{The future of community-tourism spaces}

The problematic case of Katuaq reveals broader issues connected with emerging cultural tourism trends. As cultural tourists seek more and more windows onto everyday life, and demand to share local community spaces with residents, we see the emergence of a new kind of space: a community-tourism space. Users of these spaces must confront not only the social conflicts already existent in the local community, but the conflicts that come with residents and visitors expecting to share a space on an equal level. It is a commendable goal to work towards the successful creation of these spaces, but one which is incredibly complex and which this case study shows is hard to achieve (particularly in contexts like Greenland and other Arctic colonial or post-colonial destinations, which already experience social conflicts). 
Further research should investigate other examples of the emergence of community-tourism spaces and examine their effectiveness to work towards an understanding of how these positive interactions can be successfully achieved - in other words, how we can please the cultural tourists of the future. What is important to take away from this paper in further research is the meeting of academic fields that is necessary in order to develop a full understanding of this emerging phenomenon. Further research should find its foundation in the combination of theory and learning from both tourism and leisure/recreational studies. Understanding emerging trends within tourism often requires input from other fields, and with this input, researchers can work towards finding an answer to the question of whether or not "community spaces" can successfully operate for more than one community.

\section{Conclusion}

The field of tourism studies is riddled with dichotomies and conflicts; after all, the concept of tourism itself is based on the meeting of a person with a strange place, or the meeting of two people from cultures and places alien to each other (Hollinshead, 2006). What the case of Katuaq teaches us about developing and constructing places for tourism is that the simple placing together of two things that are somehow in conflict with one another does not create interaction and understanding. Much of the theory I have cited regarding cultural encounters and placemaking in contexts of cultural conflict suggests that it is this simple; however, in the case of Katuaq, different groups and purposes have found a way to work around each other in a fashion that infinitely avoids the kinds of meetings that many expect the centre to provide.

Although this paper argues that Katuaq is not successful in this regard, what the case of Katuaq and the growth of cultural centres as tourism spaces reveals on a broader level is perhaps a trend for community spaces to become simultaneously spaces for tourism. It is argued that "new cultural tourists", who increasingly demand access to locals' everyday lives, could be satisfied by these kinds of community-tourism spaces, which have the potential to be an appropriate, stimulating and constructive platform for the forging of understandings between locals and tourists. However, further research is required in order to understand how these spaces could be operated to the benefit of all groups involved. It has been argued that this research should find its theoretical foundation at the intersection of tourism and leisure studies.

\section{References}

Aelbrecht, P. (2016), “'Fourth places': the contemporary public settings for informal social interaction among strangers", Journal of Urban Design, Vol. 21 No. 1, pp. 124-52.

Alivizatou, M. (2011), "Intangible heritage and erasure: rethinking cultural preservation and contemporary museum practice”, International Journal of Cultural Property, Vol. 18 No. 1, pp. 37-60.

Allport, G.W., Clark, K. and Pettigrew, T. (1954), The Nature of Prejudice, Addison-Wesley, Boston, MA.

Bernard, R.H. (2011), Research Methods in Anthropology: Qualitative and Quantitative Approaches, 5th ed., AltaMira Press, Walnut Creek, CA.

Bresner, K. (2014), "Sharing identity through indigenous Tourism: Osoyoos Indian Band's Nk'mip desert cultural centre", Anthropologica, Vol. 56 No. 1, pp. 135-50.

Bruner, E.M. (2005), "Introduction: travel stories told and retold", in Bruner, E.M. and Bruner, E.M. (Eds), Culture on Tour: Ethnographies of Travel, Chicago University Press, Chicago, IL, pp. 1-29.

Clifford, J. (1988), The Predicament of Culture, Harvard University Press, Cambridge, MA.

Crick, P. (2015), "New third places: opportunities and challenges", in Woodside, A. (Ed.), Tourism Sensemaking: Strategies to Give Meaning to Experience, Emerald Group Publishing, Bingley, pp. 63-77.

Glover, T.D. (2004), "Social capital in the lived experiences of community gardeners", Leisure Sciences, Vol. 26 No. 2, pp. 143-162.

Hannam, K. and Knox, D. (2011), Researching Tourism. Understanding Tourism: A Critical Introduction, SAGE Publications, London. 
Hollinshead, K. (2006), "The shift to constructivism in social inquiry: some pointers for tourism studies", Tourism Recreation Research, Vol. 31 No. 2, pp. 43-58.

Jackman, M.R. and Crane, M. (1986), "'Some of my best friends are black...': interracial friendship and whites' racial attitudes", Public Opinion Quarterly, Vol. 50 No. 4, pp. 459-86.

Jorgensen, D.L. (1989/2011), The Methodology of Participant Observation, SAGE, Thousand Oaks, CA, pp. 12-26.

Katuaq (2017), Katuaq 1997-2017, available at: https://katuaq.gl/da/Om-Katuaq/Nyheder/Katuaq-1997-20 17-jubilaeumsbog

Oldenburg, R. and Brissett, D. (1982), "The third place”, Qualitative Sociology, Vol. 5 No. 4, pp. 265-84.

Ortner, S.B. (2006), Anthropology and Social Theory, Culture, Power, and the Acting Subject, Duke University Press, Durham, NC.

Pratt, M.L. (1991), "Arts of the contact zone”, Profession, pp. 33-40.

Richards, G. (2007), Cultural Tourism: Global and Local Perspectives, Psychology Press.

Schorch, P. (2013), "Contact zones, third spaces, and the act of interpretation”, Museum and Society, Vol. 11 No. 1 , pp. $68-81$.

Selka, S. (2013), "Cityscapes and contact zones: Christianity, Candomblé, and African heritage tourism in Brazil”, Religion, Vol. 43 No. 3, pp. 403-20.

Shinew, K.J., Glover, T.D. and Parry, D.C. (2004), "Leisure spaces as potential sites for interracial interaction: community gardens in urban areas", Journal of Leisure Research, Vol. 36 No. 3, pp. 336-55.

Slater, A. and Jung Koo, H. (2010), "A new type of 'third place'?", Journal of Place Management and Development, Vol. 3 No. 2, pp. 99-112.

Stern, P.R. and Stevenson, L. (Eds) (2006), Critical Inuit Studies: An Anthology of Contemporary Arctic Ethnography, University of Nebraska Press, Lincoln, NE.

Suchman, E.A. (1964), Strangers Next Door. Ethnic Relations in American communities, Upper Saddle River, Prentice-Hall, NJ.

Tourismstat.gl (2018), "Greenland Tourism statistics”, available at: http://tourismstat.gl/ (accessed 15 July 2018).

Visit Greenland (2018), “Tourism statistics report 2017”, available at: tourismstat.gl (accessed 6 April 2018).

Wachowich, N. (2006), "Cultural survival and the trade in Iglulingmiut traditions", in Stern, P.R. and Stevenson, L. (Eds), Critical Inuit Studies: An Anthology of Contemporary Arctic Ethnography, University of Nebraska Press, Lincoln, NE, pp. 119-38.

\section{Corresponding author}

Elizabeth Ann Cooper can be contacted at: coopsikins@gmail.com

For instructions on how to order reprints of this article, please visit our website: 